\title{
Medical Ultrasonography - former Romanian Journal of Ultra- sonography - 20 years since the first issue
}

\section{Petru Adrian Mircea}

Medical Clinic I, Dept. Gastroenterology, 'Iuliu Hatieganu” University of Medicine and Pharmacy, Cluj-Napoca, Romania

Most often than not, submerged in our daily routines and perhaps making an erroneous judgement of the value of events, we tend to forget important dates or simply believe they could be overlooked in silence. It happens to all of us and it is part of our lives. However, there are landmarks that must be treasured because they indicate the beginning and, eventually, the development of something to which people, teachers and mentors, friends and opponents even have all contributed.

The publication of the first issue of the Romanian Journal of Ultrasonography ("Revista Română de Ultrasonografie") 20 years ago is indeed a landmark, an event. Twenty years signify a long pathway over which originally difficult steps were taken, but where also an invaluable experience was acquired. This experience is now to be found in the very substance of the current Medical Ultrasonography journal.

The facts first. Revista Română de Ultrasonografie (the Romanian Journal of Ultrasonography) first appeared among the medical scientific publications in Romania in May 1999. It was based on the activity of the recently established Romanian Society for Ultrasonography in Medicine and Biology - SRUMB (1997) and thanks to the enthusiasm of a group of young specialists in diagnostic ultrasound, most of them within the Ultrasound Education Centre of the "Iuliu Haţieganu" Medicine and Pharmacy University of Cluj.

Received Accepted

Med Ultrason

2019, Vol. 21, No 2, 107-108

Corresponding author: Prof. dr. Petru Adrian Mircea

Medical Clinic I, Dept. Gastroenterology,

Emergency Clinical County Hospital

"Iuliu Haţieganu" University of Medicine

and Pharmacy Cluj-Napoca, 3-5 Clinicilor str.,

400006, Cluj-Napoca, Romania

e-mail:pmircea@umfcluj.ro
Twenty years from the first issue of the journal, I am quoting from the editorial I wrote on that occasion: "This initiative relies on many reasons... Among them, the ever larger number of physicians who practice ultrasonography and their wish, as voiced on numerous occasions, to improve, to exchange views and share their personal experience. This is a stimulating real context, just as real as the suitability to all medical specialties, which is specific to ultrasound exploration...." Moreover, the ultrasonography training centres had started to develop in Romania and the National Professional Society in the field had just been established itself.

From the very beginning the journal consistently pursued a set of clear objectives and, as a result, its standard in quality rose steadily, as well as the interest in the journal. It aimed to "become a dynamic presence among the national medical publications, to be open and welcoming to all those who would wish to make their voice heard in its pages, but also demanding in the scientific and professional approach in the field."

To this end, the journal has always fostered the utmost scientific responsibility, guaranteed by the most renowned Romanian specialists, as well as by many foreign contributors. We have also been aware of our duty to support the educational role of the journal, and I quote: "...we are fully aware of the equally important task we have undertaken, beside supporting scientific research. In order to make progress in terms of method and methodology, we must use the same language, the same diagnostic algorithms, we need to educate and, not least, to educate ourselves."

On this basis, the journal was published in Romanian during its first ten years; it gained in substance and national recognition, including by bodies such as the National Council for Scientific Research in Higher Education and the Romanian College of Physicians. The journal's content structure became, step by step, better defined, includ- 
ing, beside the editorials and letters, original articles, reviews, pictorial essays, interdisciplinary pieces, such as the sequence entitled „The Anatomy Lesson" or "How to do", articles on continuing medical education (among which a series over several years on scientific writing and publishing), case reports and image quizzes, as well as news from the SRUMB, EFSUMB or on past and future scientific events. The journal pages quickly acquired an academic set format that was also retained by Medical Ultrasonography.

However, keeping our journal alive was no easy task, especially because of financial constraints, but also because we could not rely on a constant number of contributors, mainly in the beginning. As the years went by, we reached an ever higher quality standard for content and layout, which made us proud of our achievement, at least at the national level.

But we did not stop there, we thought we had not done enough.

The turning point was in 2008, at the Euroson Congress in Timisoara, when the Board of the Journal took the decision to convert it into an English language journal renamed "Medical Ultrasonography". The mission statement promised to make it available to a wider audience and give it a wider circulation. In my editorial at the time, entitled "Need for change", I stated: “...Our journal is approaching its tenth year of existence. We believe that, in the course of these years, it has met its purpose and fulfilled its initial objectives, especially those of promoting high quality standards for the practice of ultrasonography, achieving performance in training in ultrasonography and sharing important experiences between Romanian specialists."

Our achievements were admirable, but insufficient in order to join the international circuit. As I showed before, eleven years ago the Board of the Journal suggested therefore several changes, among which the most important was to convert the journal into an English language publication. I believe this was an excellent choice, just as several other decisions that followed and led to deep changes concerning the Board, the peer-review requirements, the contributors' renown and professionalism. With Daniela Fodor as editor-in-chief, all these set the quality and visibility of the journal on an ascending path, as it was first included in PubMed and then in the ISI Thompson database (currently Clarivate Analytics), with a rising impact factor.

It is my personal belief that the whole 20 -year evolution of the journal reflects the perseverant effort of a team of enthusiastic professionals and that it has more than fulfilled the purpose for which it was set up and the objectives stated from the very first issue.

As I am strongly connected to this story that I wrote together with my friends Radu Badea, Sorin Dudea, Ioan Sporea and Daniela Fodor, among whom our mentor Professor Gheorghe Jovin played the invaluable master role, I wish the journal to maintain its current growth and its openness to the medical world and the demanding standards that have achieved its current position.

And, as we are in the world of ultrasound, I cannot help but remember the words with which I optimistically concluded my first editorial 20 years ago; I believe they still hold the same significance for the current ultrasonography journal:

"...for the rest, we hope that our initiative shall set off enough... positive echoes and that it will enjoy a path with the least artefacts!"

\section{Professor Petru Adrian Mircea}

Medical Ultrasonography

(former "Revista Română de Ultrasonografie") 